\title{
Effect of Quaternary Cations on the Electrochemical Synthesis of Polyaniline and Its Degradation
}

\author{
Li Sun, Han-Chang ZHANG, ${ }^{\dagger}$ Chun-Ming JIANG, Qian-Rong LI, and Ru-Ke BAI \\ School of Chemistry and Materials Science, University of Science and Technology of China, \\ Hefei, Anhui 200326, P. R. China
}

(Received November 9, 2004; Accepted January 31, 2005; Published May 15, 2005)

\begin{abstract}
Polyaniline(PANI) was prepared by adding three different quaternary ammonium salts to $\mathrm{H}_{2} \mathrm{SO}_{4}$ electrolyte and the effect of the cations on the electrochemical degradation of PANI film was researched. The electropolymerized films were characterized by cyclic voltammetry, UV-vis spectroscopy and scanning electron microscopy. The result showed that quaternary cations hindered gradually the polymerization of aniline with increase of the size, which made the porosity of the film smaller and the morphology more compact compared with pure PANI films. Although the cations didn't change the electrode reactive process of PANI, they affected the oxidation velocity of the films and the degradation rate of PANI in the following order: $\mathrm{Bu}_{4} \mathrm{~N}^{+}>\mathrm{Et}_{4} \mathrm{~N}^{+}>\mathrm{Me}_{4} \mathrm{~N}^{+}$, and the stability of the films was enhanced. [DOI 10.1295/polymj.37.350]

KEY WORDS Polyaniline / Quaternary Cations / Electrochemical Degradation /
\end{abstract}

PANI is considered to be the most promising conducting polymers due to its high electrical conductivity, excellent environmental stability, low-cost and easy preparation. ${ }^{1}$ The electrochemical stability of PANI and related materials is of great importance for their possible use in various electrochemical systems and devices, such as rechargeable batteries, electrochromic displays and sensors, etc. ${ }^{2-6}$ Therefore, much attention has been paid to study the stability and degradation of PANI.

Up to now, discussing the effect of the nature and size of cations on PANI films is very significant for the preparation of PANI with good properties and extensive applications and many papers about simple inorganic cations have been reported. Min et al. ${ }^{7}$ synthesized PANI with high molecular weight by the technique of adding inorganic salts. Boroleet et al. ${ }^{8}$ prepared PANI films doped by several inorganic salts with various sizes of cations $\left(\mathrm{K}^{+}, \mathrm{Na}^{+}, \mathrm{Li}^{+}, \mathrm{Mg}^{2+}\right)$ and found that the conductivity of the films was increased. He et al. ${ }^{9}$ found that alkaline metal cations obviously accelerated the growth rate of PANI films in the following order: $\mathrm{K}^{+}>\mathrm{Na}^{+}>\mathrm{Li}^{+}>\mathrm{H}^{+}$by employing ellipsometry and electrochemical methods. Giovani et al. ${ }^{10}$ also prepared PANI films in aniline solution containing different alkaline metal cations and found that the variation of the scan rate for only the first cycle affected the morphology, and therefore the electrical properties of PANI films grown potentiodynamically. However, only scarce information was available in the effect of quaternary cations on properties of PANI. The present work showed that quaternary cations hindered the degradation of the films, and the trends increased with the augment of the cations.

In this paper we discussed the polymerization of aniline in $\mathrm{H}_{2} \mathrm{SO}_{4}$ solution containing different quaternary cations $\left(\mathrm{Me}_{4} \mathrm{~N}^{+}, \mathrm{Et}_{4} \mathrm{~N}^{+}, \mathrm{Bu}_{4} \mathrm{~N}^{+}\right)$and the effect of cations on the degradation of PANI films in $\mathrm{H}_{2} \mathrm{SO}_{4}$ in detail by UV-vis absorption spectra and cyclic voltammetry.

\section{EXPERIMENTAL}

All chemicals (aniline, $\mathrm{H}_{2} \mathrm{SO}_{4}, \mathrm{Me}_{4} \mathrm{NBr}, \mathrm{Et}_{4} \mathrm{NBr}$, $\mathrm{Bu}_{4} \mathrm{NBr}$ ) were of $\mathrm{AR}$ grade and used without further purification. Doubly distilled water was employed to prepare all solutions. The electrochemical synthesis and characterization of PANI were carried out at room temperature in a standard three-electrode cell. The cell consisted of a platinum (Pt) wire ( $c a .5 \mathrm{~mm}$ length and $0.5 \mathrm{~mm}$ diameter) or glassy carbon (GC) $(c a .3 .0 \mathrm{~mm}$ diameter) working electrode, a platinum wire counter electrode and a saturated calomel (SCE) reference electrode. All potentials given were referred to the SCE. Prior to each experiment, the Pt wire was carefully rinsed in distilled water and $5 \mathrm{~min}$ immersion in concentrated $\mathrm{HNO}_{3}$ before it was finally dried on clean laboratory tissues.

The films were electropolymerized in a solution containing $0.1 \mathrm{~mol} / \mathrm{L}$ aniline, $1 \mathrm{~mol} / \mathrm{L} \mathrm{H}_{2} \mathrm{SO}_{4}$ as electrolyte and $0.1 \mathrm{~mol} / \mathrm{L}$ quaternary ammonium salts by potential cycling at $50 \mathrm{mV} / \mathrm{s}$ between -0.2 and 1.0 $\mathrm{V}$. The experiments on the electrochemical degradation of PANI films were performed by holding the films in $1 \mathrm{~mol} / \mathrm{L}_{2} \mathrm{SO}_{4}$ under the same potential

${ }^{\dagger}$ To whom correspondence should be addressed (Tel: +86-551-3606693, E-mail: zhcww@ustc.edu.cn). 
range and scan rate for 30 cycles. An automated LK98B II electrochemical measurement system provided the necessary potential and current control. The optical absorption was carried out by UV-vis spectrophotometer (UV-2401PC). All the spectra were recorded in the wavelength range of $230-270 \mathrm{~nm}$. The morphology of PANI deposited on GC was examined by a scanning electron microscopy (SEM, x-650).

\section{RESULTS AND DISCUSSION}

Figure 1 presented cyclic voltammogram during PANI film growth on a Pt electrode. The film was formed by cycling at $50 \mathrm{mV} / \mathrm{s}$ between -0.2 and $1.0 \mathrm{~V} v s$. SCE in a solution of $0.1 \mathrm{~mol} / \mathrm{L}$ aniline and $1 \mathrm{~mol} / \mathrm{L} \mathrm{H}_{2} \mathrm{SO}_{4}$. The electrochemical polymerization characteristics of PANI in aqueous solution of $\mathrm{H}_{2} \mathrm{SO}_{4}$ as electrolyte in presence of salts were almost the same compared with pure PANI, but the difference of the values of peak currents were mainly attributed to the quaternary cations in the forming electrolyte. It also reflected the effect of quaternary cations on the polymerization of aniline, which was more directly found from the dependence of the current of the first oxidation peak $\left(I_{\mathrm{A}}\right)$ and time $(t)$, as shown in Figure 2. It could be seen that curve a showed the relationship of $I_{\mathrm{A}}$ and $t$ of the polymerization of pure aniline solution. At the beginning, the polymerization was very slow, and the change of current was unapparent. After 6 min $I_{\mathrm{A}}$ increased quickly with time due to the autoacceleration effect of the polymerization of aniline. Curves b, c and d corresponded to the polymerization of aniline in electrolyte containing quaternary ammonium salts. Primarily the currents changed faintly, they started to rise slowly until $8 \mathrm{~min}$, but none of them exceeded that of curve a. This probably meant that quaternary cations hindered the polymerization of aniline, and the prohibitive degree was $\mathrm{Me}_{4} \mathrm{~N}^{+}<$ $\mathrm{Et}_{4} \mathrm{~N}^{+}<\mathrm{Bu}_{4} \mathrm{~N}^{+}$, namely the larger the size of quater-

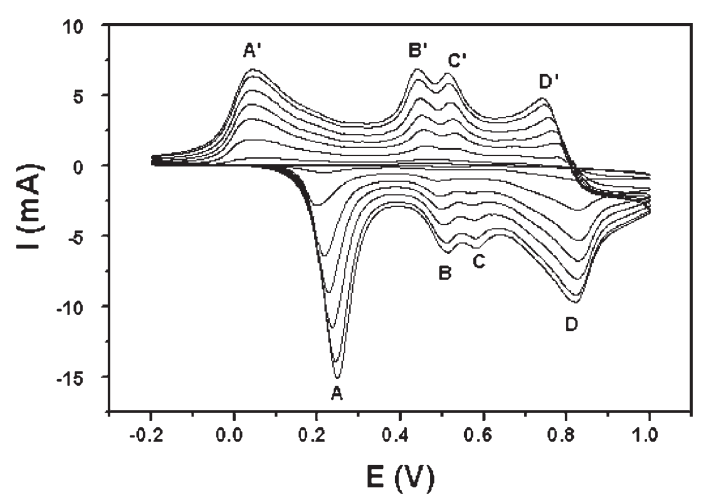

Figure 1. Cyclic voltammograms of PANI films in $0.1 \mathrm{~mol} / \mathrm{L}$ aniline $+1 \mathrm{~mol} / \mathrm{L} \mathrm{H}_{2} \mathrm{SO}_{4}$ between -0.2 and $1.0 \mathrm{~V}$ at a scan rate of $50 \mathrm{mV} \mathrm{s}^{-1}$.

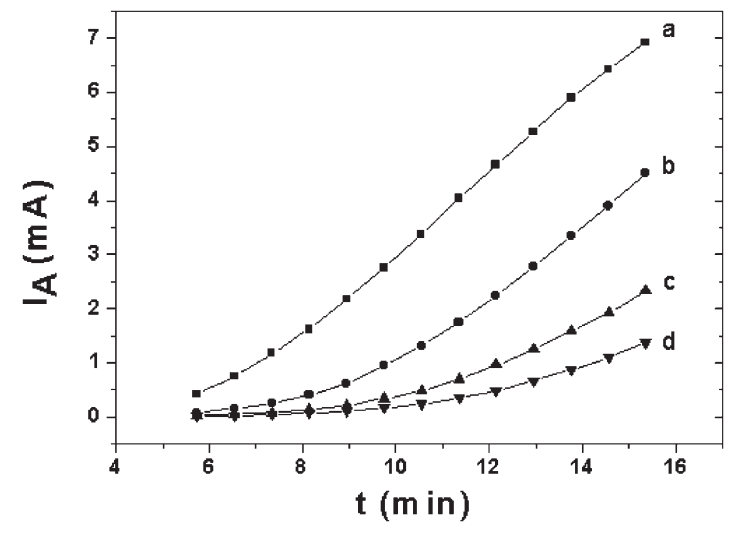

Figure 2. Dependence of $I_{\mathrm{A}}$ on $t$ during the electropolymerization of solution containing (a) $0.1 \mathrm{~mol} / \mathrm{L}$ aniline $+1 \mathrm{~mol} / \mathrm{L}$ $\mathrm{H}_{2} \mathrm{SO}_{4}$; (b) $0.1 \mathrm{~mol} / \mathrm{L}$ aniline $+1 \mathrm{~mol} / \mathrm{L} \mathrm{H}_{2} \mathrm{SO}_{4}+0.1 \mathrm{~mol} / \mathrm{L}$ $\mathrm{Me}_{4} \mathrm{NBr}$; (c) $0.1 \mathrm{~mol} / \mathrm{L}$ aniline $+1 \mathrm{~mol} / \mathrm{L} \mathrm{H}_{2} \mathrm{SO}_{4}+0.1 \mathrm{~mol} / \mathrm{L}$ $\mathrm{Et}_{4} \mathrm{NBr}$; (d) $0.1 \mathrm{~mol} / \mathrm{L}$ aniline $+1 \mathrm{~mol} / \mathrm{L} \mathrm{H}_{2} \mathrm{SO}_{4}+0.1 \mathrm{~mol} / \mathrm{L}$ $\mathrm{Bu}_{4} \mathrm{NBr}$.

nary cations, the higher was its prohibitive effect on the polymerization of aniline, and the smaller was the peak current $I_{\mathrm{A}}$.

This possible reason was that the electropolymerization of aniline was initiated by aniline cation-radical, and three cations were positively charged. Because of repulsion each other with the same nature, the cations hindered the polymerization of PANI to a certain extent. ${ }^{11}$ The radius of the cations increased with the increase of the number of carbon atoms in alkyl, which resulted in the increase of the effect of the cations on the reaction among aniline cation-radicals in the polymerization solution. Namely the polymerization of aniline decreased gradually with the increase of the radius. From SEM images of PANI films (Figure 3), we could see that the granule on the surface also became smaller accordingly with increase the size of the cations, the porosity of PANI films became smaller, and the films became more compact, which reflected the effect of cations on the microtopography and the stability of the films.

Figure 4 could be obtained by holding the PANI films previously deposited in $1 \mathrm{~mol} / \mathrm{L} \mathrm{H}_{2} \mathrm{SO}_{4}$ for 30 cycles. It could be seen that the currents of peaks a and $\mathrm{d}$ descended and middle peaks ascended with the cycle number increasing, which embodied the degradation course of the PANI film. The oxidation peaks a and $\mathrm{d}$ could be assigned to the leucoemeraldine/ emeraldine and emeraldine/pernigraniline redox transitions of PANI (eqs 1 and 2), respectively. The middle peaks $b$ and $c$ were associated with the products of the PANI degradation, most probably benzoquinone/ hydroquinone (BQ/HQ) and p-aminophenol/p-quinoneimine (PAP/QI) redox couples (eqs 4-6), ${ }^{12-17}$ and these eqs $1-6$ could be shown as follows: 


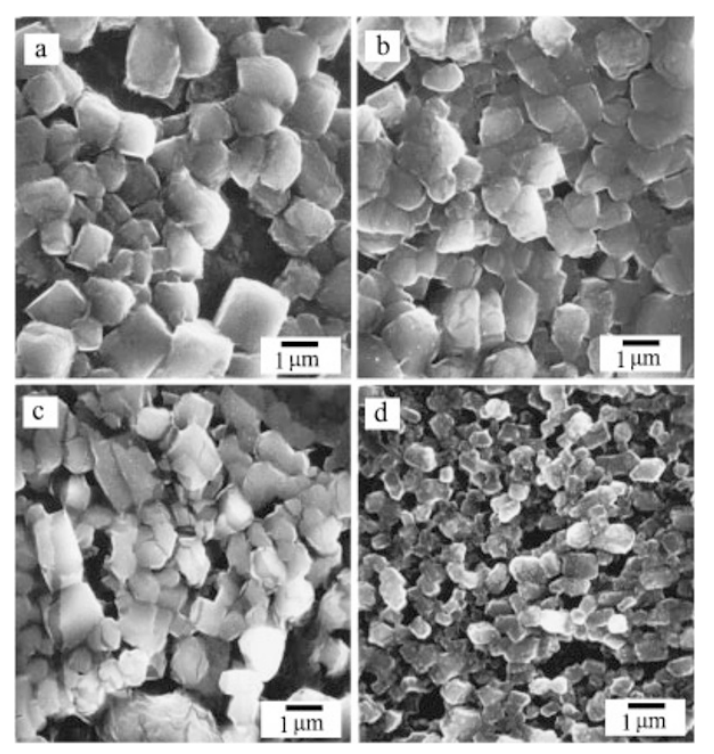

Figure 3. SEM images of four PANI films. The polymerization condition as indicated in Figure 2.

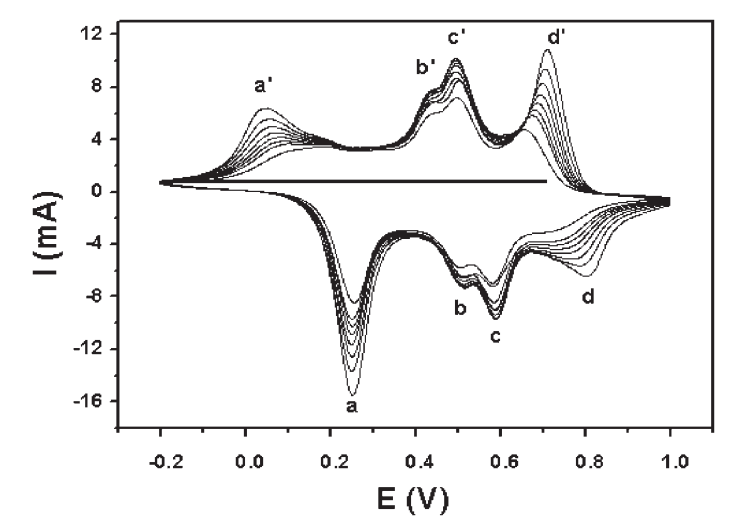

Figure 4. Cyclic voltammograms of the PANI films in $1 \mathrm{~mol} /$ $\mathrm{L}_{2} \mathrm{SO}_{4}$. The films are prepared in $0.1 \mathrm{~mol} / \mathrm{L}$ aniline $+1 \mathrm{~mol} / \mathrm{L}$ $\mathrm{H}_{2} \mathrm{SO}_{4}$ between -0.2 and $1.0 \mathrm{~V}$ at a scan rate of $50 \mathrm{mV} \mathrm{s}^{-1}$ for 30 cycles.
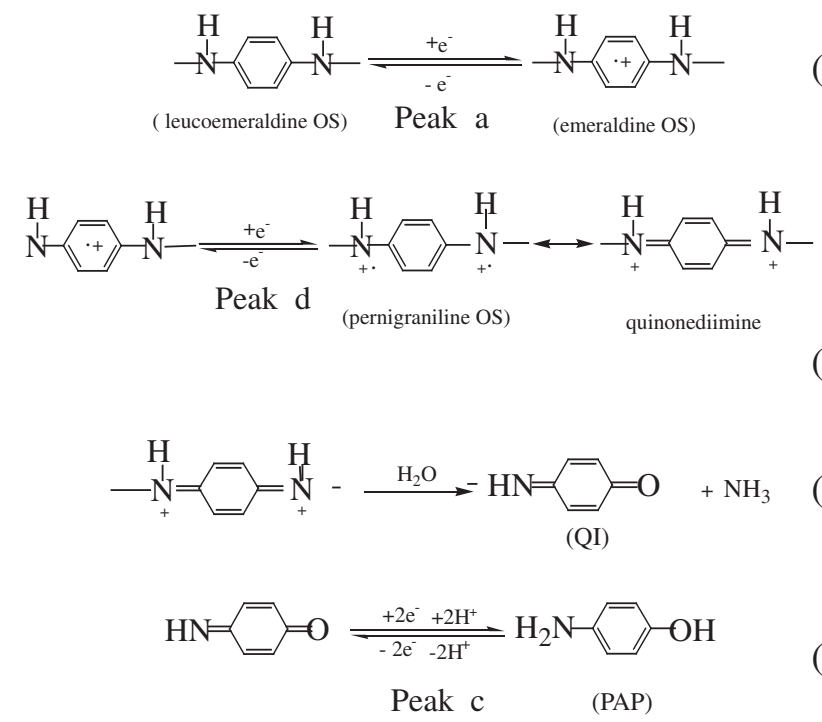

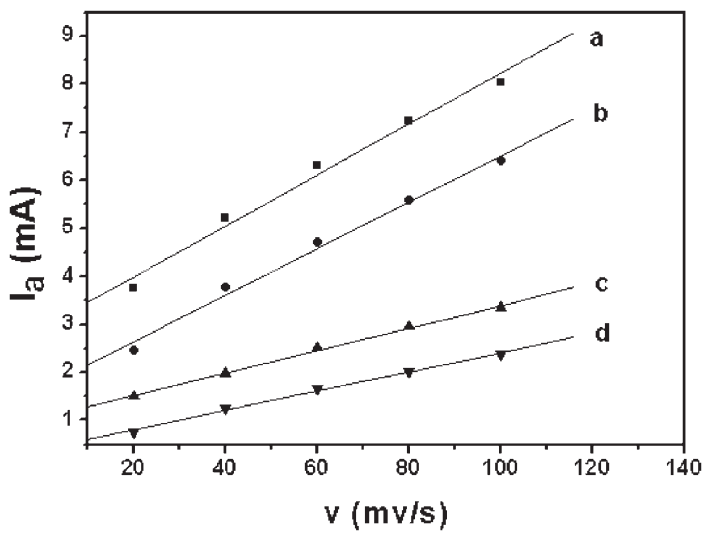

Figure 5. Relationships between $I_{\mathrm{a}}$ and $v$ during the degradation of the PANI films. The same quality films were prepared in solution containing (a-d) as indicated in Figure 2.

$$
\begin{aligned}
& \mathrm{HN}=\Longrightarrow=\mathrm{O}+\mathrm{H}_{2} \mathbf{O} \stackrel{+\mathrm{H}^{+}}{\longrightarrow} \mathrm{O} \underset{(\mathrm{BQ})}{\rightleftharpoons}=\mathrm{O}+\mathrm{NH}_{4}^{+}
\end{aligned}
$$

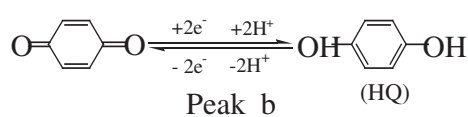

The relationships between the first oxidation peak currents $\left(I_{\mathrm{a}}\right)$ and scan rate $(v)$ were shown in Figure 5. All the four curves displayed good linear relationships, which demonstrated that four films had the same reactive process of electrode. So it could be concluded that the electron transfer reactions of the films were probably the rate-determining steps. We also observed that the height of the $I_{\mathrm{a}}-v$ curve slopes was discriminative in the following order: base $>\mathrm{Me}_{4} \mathrm{~N}^{+}>$ $\mathrm{Et}_{4} \mathrm{~N}^{+}>\mathrm{Bu}_{4} \mathrm{~N}^{+}$, although their reactive process were similar. As we know, the results clearly reflected the effect of cations on the oxidation velocity of the films.

Preparing four PANI films with various cations and the same electric quantity $(114 \mathrm{mC})$ by the different of the number of cycles and cycling the films in $1 \mathrm{~mol} / \mathrm{L}$ $\mathrm{H}_{2} \mathrm{SO}_{4}$ solution for 30 cycles, we analyzed the degradation solutions and thought that $\mathrm{BQ}$ was the major soluble degradation product of PANI film in $\mathrm{H}_{2} \mathrm{SO}_{4}$, which was also reported in the literature. ${ }^{18-21}$ Utilizing the generative rate of the product QI and the absorption spectra of $\mathrm{BQ}$ in the degradation solution to measure the extent of the films degradation in $\mathrm{H}_{2} \mathrm{SO}_{4}$, the results were shown in Figures 6 and 7. In Figure 6, the peak current of the third anodic wave (peak c) had been plotted $v s$. cycle number at a constant scan rate. It could be seen that the peak current $I_{\mathrm{c}}$ was the highest, when the film was prepared in pure aniline solution, and the increment was very big with the cycle number increasing. However, the incremental rate of $I_{\mathrm{c}}$ started to descend gradually in the presence of salts. Table I listed the generative rate of the product QI, 


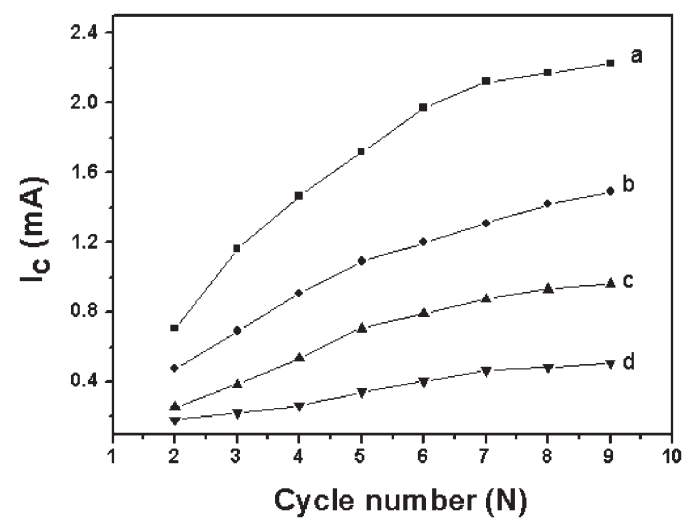

Figure 6. Relationships between $I_{\mathrm{c}}$ and $N$ during the degradation of PANI films in $1 \mathrm{~mol} / \mathrm{L} \mathrm{H}_{2} \mathrm{SO}_{4}$. The films were prepared as indicated in Figure 2.

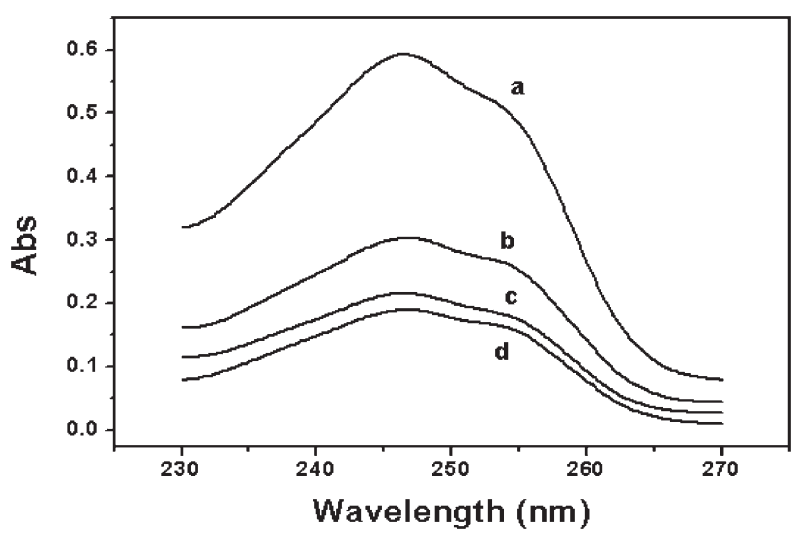

Figure 7. UV-vis spectra of BQ in the degradation solution.

Table I. The rate of change of peak c currents vs. cycle number in $\mathrm{H}_{2} \mathrm{SO}_{4}$ with and without salts

\begin{tabular}{ccccc}
\hline & Base & $\mathrm{Me}_{4} \mathrm{~N}^{+}$ & $\mathrm{Et}_{4} \mathrm{~N}^{+}$ & $\mathrm{Bu}_{4} \mathrm{~N}^{+}$ \\
\hline Growth rate $(\mathrm{mA} /$ cycle $)$ & 0.213 & 0.144 & 0.105 & 0.051 \\
\hline
\end{tabular}

which was monitored from the variation of anodic peak current $\left(I_{\mathrm{c}}\right)$ vs. cycle number in $\mathrm{H}_{2} \mathrm{SO}_{4}$. It was clear that the growth rate of product QI in the presence of salts decreased compared with pure PANI film. This meant that they generated QI with the order: base $>\mathrm{Me}_{4} \mathrm{~N}^{+}>\mathrm{Et}_{4} \mathrm{~N}^{+}>\mathrm{Bu}_{4} \mathrm{~N}^{+}$. Obviously, this relationship also reflected the degradation degree of four PANI films.

Figure 7 showed the UV-vis absorption spectra of $\mathrm{BQ}$ in the degradation solution. It was known that there was a stronger absorption of $\mathrm{BQ}$ in the range of $230-270 \mathrm{~nm}$, and the absorption of BQ reached a maximum value at $246 \mathrm{~nm}$. The addition of salts had resulted in a decrease in absorbency values of BQ (Table II). The order of absorbency was base $>$ $\mathrm{Me}_{4} \mathrm{~N}^{+}>\mathrm{Et}_{4} \mathrm{~N}^{+}>\mathrm{Bu}_{4} \mathrm{~N}^{+}$in turn. This also implied that the content of BQ in the degradation solution was degressive gently. In other words, the absorption of
Table II. Absorbency values of $\mathrm{BQ}$ in $\mathrm{H}_{2} \mathrm{SO}_{4}$ with and without salts $\left(\lambda_{\max }=246.5 \mathrm{~nm}\right)$

\begin{tabular}{ccccc}
\hline & Base & $\mathrm{Me}_{4} \mathrm{~N}^{+}$ & $\mathrm{Et}_{4} \mathrm{~N}^{+}$ & $\mathrm{Bu}_{4} \mathrm{~N}^{+}$ \\
\hline Absorbency & 0.594 & 0.303 & 0.215 & 0.190 \\
\hline
\end{tabular}

degradation solution was in good agreement with the results in Figure 6, which showed that the degradation rate of PANI films dropped with the size of the cations increasing.

From the experiment and eqs 3-6 of the degradation, we could presume that the restriction mechanism of the cations was attributed to the prohibitive effect of it on the polymerization of aniline. In general, there was certain inside contact between polymerization and degradation, namely the fast-polymerized rate was in favor of loose film and accelerated the degradation of the film, which could be confirmed by cyclic voltammogram, SEM images and UV-vis absorption spectra. The presence of the cations affected the polymerization mechanism and changed the chemical physics properties of PANI films to a certain extent. As a result, the porosity of PANI films became small, and the structure of the films also became more compact, which would be more resistant to polymer degradation and enhance the electrochemical stability of the films, because it imposed large restriction on the access of the polymer interior by any solution constituents. On the side, the number of electro-active point was also one factor that affected the polymerization rate and the degradation rate of PANI film.

\section{CONCLUSIONS}

In this paper we mainly investigated the effect of quaternary cations on the polymerization rate and the degradation of the films, when aniline was polymerized in electrolyte containing quaternary ammonium salts. The results showed that after adding quaternary ammonium salts, both the polymerization of aniline and the degradation of the films dropped, and the trends increased with the augment of the cations, as compared to pure aniline. Meanwhile, the addition of salts changed the physical structure, and made PANI films more compact. The prohibitive action of the cations had certain significance, for example, they could raise the anti-oxidation of PANI so that it could be even suitable to secondary batteries and sensors etc.

\section{REFERENCES}

1. M. L. Liu, S. J. Visco, and L. C. Dejonghe, J. Electrochem. Soc., 138, 1896 (1991).

2. T. Kobayashi, H. Yaneyama, and H. Tamura, J. Electroanal. 
Chem., 161, 419 (1984).

3. L. M. Goldenberg, M. C. Petty, and A. P. Monkman, J. Electrochem. Soc., 141, 1573 (1994).

4. C. Barbero, M. C. Miras, B. Schryder, O. Haas, and R. Kotz, J. Mater. Chem., 4, 1775 (1994).

5. G. Mengole, M. M. Musiani, G. Zotti, and S. Valcher, J. Electroanal. Chem., 202, 217 (1986).

6. L. Doubova, G. Mengoli, M. M. Musiani, and A. Valcher, Electrochim. Acta, 34, 337 (1989).

7. G. Min, Synth. Met., 119, 273 (2001).

8. D. D. Borole, U. R. Kapadi, P. P. Kumbhar, and D. G. Hundiwale, Mater. Lett., 57, 844 (2002).

9. C. L. He and Y. Gao, J. Yu. Zhou. U., 19, 60 (2002).

10. G. T. Andrade, M. J. Aguirre, and S. R. Biaggio, Electrochim. Acta, 44, 633 (1998).

11. L. T. Cai, S. B. Yao, and S. M. Zhou, Chem. J. Chin. U., 17, 269 (1996).

12. D. E. Stilwell and S. M. Park, J. Electrochem. Soc., 135, 2254 (1988).
13. D. E. Stilwell and S. M. Park, J. Electrochem. Soc., 136, 688 (1989).

14. Z. H. Wang, X. Xun, Y. R. Wu, and Y. H. Tang, J. Electroanal. Chem., 464, 181 (1999).

15. A. Q. Zhang, C. Q. Cui, and J. Y. Lee, Synth. Met., 72, 217 (1995).

16. L. Duic, Z. Mandic, and S. Kovac, Electrochim. Acta, 40, 1681 (1995).

17. J. Stejskal, P. Kratochvil, and M. Spirkova, Polymer, 36, 4135 (1995).

18. R. L. Hand and R. F. Nelson, J. Am. Chem. Soc., 96, 850 (1974).

19. T. Kobayashi, H. Yoneyama, and H. Tamura, J. Electroanal. Chem., 177, 293 (1984).

20. D. E. Stilwell and S.-M. Park, J. Electrochem. Soc., 135, 2497 (1988).

21. A. M. Fenelon and C. B. Breslin, Synth. Met., 144, 125 (2004). 